\title{
ORIGINAL ARTICLE \\ Epidemiology of traumatic spinal cord injuries in the Netherlands in 2010
}

\author{
JHB Nijendijk ${ }^{1}$, MWM Post ${ }^{2}$ and FWA van Asbeck ${ }^{3}$
}

\author{
Study design: Retrospective files study. \\ Objective: To update epidemiological data on the incidence of traumatic spinal cord injury (TSCI) in The Netherlands. \\ Setting: The Netherlands
}

Methods: From the Dutch National acute-care hospital database, all records of patients discharged with International Classification of Diseases 9th edition codes 806 or 952 in 2010 were selected. For each record, we requested an anonymised copy of the hospital discharge letter. We analysed the received letters for TSCl, defined as a newly acquired traumatic transverse lesion of the spinal cord or cauda equina, resulting in loss of motor, sensory, bladder or bowel function below the level of the lesion, lasting longer than 2 weeks. We further extracted data on demographic and $\mathrm{SCl}$ characteristics and discharge destination.

Results: We received 372 discharge letters or a confirmation that the patient did not have TSCI. A total of 185 patients with TSCI were identified, of whom 30 died during acute-care hospital stay. We estimated the incidence of TSCl as 14.0 per million per annum including patients and 11.7 per million per annum excluding patients who did not survive the acute phase. Most patients were male (74\%), had tetraplegia (69\%) and an motor incomplete lesion (62\%). Median age was 62 years (range 13-96). Discharge destination was a rehabilitation centre specialized in $\mathrm{SCl}$ in $78 \%$ of patients with motor complete $\mathrm{TSCl}$ and $47 \%$ of patients with motor incomplete TSCI.

Conclusion: The estimated incidence of TSCI surviving the acute phase was 11.7 per million per annum in the Netherlands in 2010. A substantial proportion of these patients was not referred to a specialized rehabilitation centre.

Spinal Cord (2014) 52, 258-263; doi:10.1038/sc.2013.180; published online 21 January 2014

Keywords: spinal cord injury; traumatic; epidemiology; incidence; The Netherlands

\section{INTRODUCTION}

The incidence of traumatic spinal cord injury (TSCI) in The Netherlands in 1994 was estimated to be 10.4 ; or 12.1 per million per annum including those who died during the acute phase. ${ }^{1}$ This is at the low end of a wide range of incidence figures from 10.4 to 83 per million per annum reported in the literature. ${ }^{2,3}$ The mean incidence number in Western Europe is 16 per million per annum. ${ }^{4}$ The low incidence in The Netherlands might reflect effective prevention in the Netherlands, for example, road traffic safety, or certain natural conditions, for example, the absence of mountains, but might also be due to chance. Moreover, it is important to monitor TSCI incidence rates over time. ${ }^{2}$ Reliable and up-to-date data on the incidence of SCI is important for health-care planning, for example, concerning rehabilitation clinics specialized in SCI and to focus preventive measures. As the most recent data on the incidence of TSCI in the Netherlands stem from 1994, it is important to check whether these figures are still valid.

In the Netherlands, patients with TSCI are first admitted to an acute-care hospital. ${ }^{1}$ From there, those who need rehabilitation treatment are usually transferred to a rehabilitation institution for in- or outpatient rehabilitation. In 1994, $70 \%$ of all TSCI patients surviving the acute phase were transferred to a rehabilitation centre or rehabilitation ward in a general hospital. ${ }^{1}$ In 2011, the Dutch Society of Physical Rehabilitation Medicine (VRA) recommended concentration of treatment of patients with recent TSCI in one of the eight rehabilitation centres with a department specialized in SCI (Behandelkader Dwarslaesie; http://dwarslaesie.nl). However, it is unknown whether this has become common practice in the Netherlands. In this study, we aim (1) to provide an up-to-date epidemiological description of TSCI in The Netherlands in 2010, and (2) to evaluate how many new patients with a TSCI were transferred to rehabilitation centres specialized in TSCI.

\section{MATERIALS AND METHODS}

We replicated as much as possible the methods of the 1994 study $^{1}$ to enable comparison with that earlier study.

\section{Patients}

Records with the International Classification of Diseases 9th edition (ICD-9) codes 806 (fracture of the spine with injury of the spinal cord) or 952 (injury to the spinal cord without apparent spinal fracture) were retrieved from the Landelijke Medische Registratie (National Medical Registration), the national database of patients hospitalised in an acute-care hospital (trauma centre or general hospital).

${ }^{1}$ Center of Excellence for Rehabilitation Medicine, University Medical Center Utrecht and De Hoogstraat Rehabilitation, Utrecht, The Netherlands; ${ }^{2}$ Brain Center Rudolf Magnus and Center of Excellence for Rehabilitation Medicine, University Medical Center Utrecht and De Hoogstraat Rehabilitation, Utrecht, The Netherlands and ${ }^{3}$ Department of Spinal Cord Management, De Hoogstraat Rehabilitation, Utrecht, The Netherlands

Correspondence: Dr MWM Post, Brain Center Rudolf Magnus and Centre of Excellence for Rehabilitation Medicine, University Medical Center Utrecht and De Hoogstraat Rehabilitation, PO Box 85238, Utrecht 3508AE, The Netherlands.

E-mail: m.post@dehoogstraat.nl

Received 27 July 2013; revised 17 November 2013; accepted 27 December 2013; published online 21 January 2014 


\section{Procedure}

The national database is managed by Dutch Hospital Data (DHD). DHD selected all records of patients with code 806 or 952 as main or concurrent diagnosis discharged in 2010. Hospitals that provided one or more of these records were invited by DHD to take part in this study, that is, to authorize DHD to provide us with the name of the hospital, the hospital patient identification number, the patient's date of birth and date of hospitalization. After checking for duplicate records, we requested the hospitals that had agreed to send us the anonymised discharge letters concerning these patients. DHD also provided us with summary statistics of all selected records on sex, mean age, mean length of hospital stay and discharge destination to allow for a nonresponse analysis.

\section{Assessments}

We analysed the discharge letters for the presence of TSCI, defined as a newly acquired traumatic transverse lesion of the spinal cord or cauda equina, resulting in loss of motor, sensory, bladder or bowel function below the level of the lesion, and lasting longer than 2 weeks. In case of transient neurological symptoms or pain only, we diagnosed this as contusion of the spinal cord. Lesion characteristics were assessed according to the International Standards for Neurological Classification of SCI. ${ }^{5}$ The American Spinal Injury Association Impairment scale classifications A and B were considered as motor complete, and the classifications $\mathrm{C}$ and $\mathrm{D}$ were considered as motor incomplete. Neurological lesion level was defined as the lowest intact motor and sensory level. Neurological levels below T1 were defined as paraplegia and neurological lesion levels at or above T1 were defined as tetraplegia.

Furthermore, data were extracted on sex, age, aetiology of injury, preexisting spinal stenosis, stabilising surgery, length of hospital stay and discharge destination. Length of stay was set at 0 if the patient died or was transferred to another hospital on the day of admission.

Approval by a Medical Ethics Review Committee was not required for this study because no patient was at risk by this study and we had access to anonymised discharge letters only, so data were not traceable to individual patients.

\section{Analyses}

Descriptive statistics were computed. Non-response analysis and comparisons with the 1994 study ${ }^{1}$ were performed using two-sided $\chi^{2}$-tests for categorical variables. To estimate the incidence of TSCI, we corrected for the nine general hospitals that did not provide data to the national database, assuming that the mean number of TSCI patients admitted to these general hospitals, and the ratio between retrieved records and patients with TSCI would be identical to those in the participating general hospitals. The Dutch population was 16.6 million in 2010, demographic data of the Dutch population in 1994 and 2010

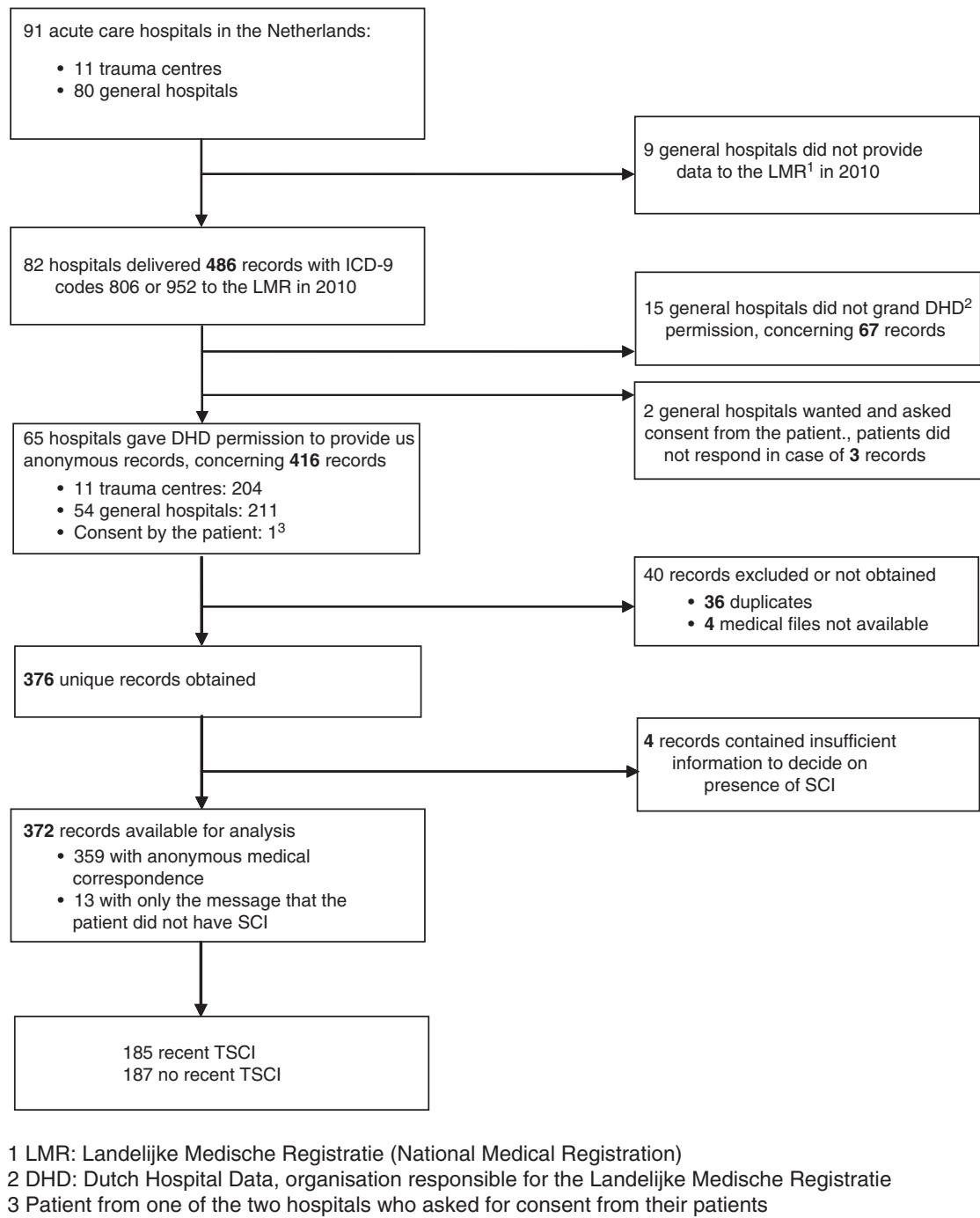

Figure 1 Flowchart retrieval of medical information LMR: Landelijke Medische Registratie (National Medical Registration), DHD: Dutch Hospital Data. 
were retrieved from the national authority for the collection of demographic data to compute the overall incidence, gender-specific incidence and agespecific incidence of TSCI (http://statline.cbs.nl). Comparison of these incidences was performed using two-sided Mid-P-Exact tests, with incidence numbers of the 1994 study $^{1}$ as expected number of cases.

\section{RESULTS}

Figure 1 gives an overview of the data acquisition. In 2010, 82 of the 91 acute-care hospitals in The Netherlands provided data to the national hospital registration system, including all eight university hospital trauma centres and all three non-university level-1 trauma centres. The nine general hospitals that did not deliver data to the national registry indicated that they were not able to determine which of their patients admitted in 2010 had an injury of the spinal cord.

A total of 486 records with ICD- 9 codes 806 or 952 were retrieved from the national hospital registration system. We got permission to receive anonymous information for 416 records. After removing 36 duplicate records, 4 records for which the medical files were untraceable and 4 records for which the discharge letter contained insufficient information to decide on the presence of TSCI, 359 discharge letters could be analysed; and for the final 13 records the hospital administrator or the physician indicated their re-evaluation prompted by our study that showed that the patient did not have SCI.

Out of 372 records, a total of 185 patients met our criteria of TSCI, of whom 30 died during acute-care hospital stay, so 155 patients with TSCI were identified who survived the hospital phase. The other 187 patients did not have TSCI. Instead, they had injuries of the spine without neurological symptoms (71), quickly passing neurological symptoms, often paresthesia or pain (69), lesions of a single radix and

Table 1 Demographic characteristics of patients with TSCI $(N=185)$

\begin{tabular}{|c|c|c|}
\hline & $\mathrm{N}$ & $\%$ \\
\hline \multicolumn{3}{|l|}{ Gender } \\
\hline Male & 137 & 74.1 \\
\hline Female & 48 & 25.9 \\
\hline \multicolumn{3}{|l|}{ Age (years) } \\
\hline $0-10$ & 0 & 0 \\
\hline $11-20$ & 19 & 10.3 \\
\hline $21-30$ & 13 & 7.0 \\
\hline $31-40$ & 17 & 9.2 \\
\hline $41-50$ & 18 & 9.7 \\
\hline $51-60$ & 21 & 11.4 \\
\hline $61-70$ & 44 & 23.8 \\
\hline $71-80$ & 27 & 14.6 \\
\hline$>80$ & 26 & 14.1 \\
\hline \multicolumn{3}{|l|}{ Types of SCl } \\
\hline Tetraplegia & 128 & 69.2 \\
\hline Motor complete ${ }^{a}$ & 32 & 17.3 \\
\hline Motor incomplete & 91 & 49.2 \\
\hline Unknown & 5 & 2.7 \\
\hline Paraplegia & 57 & 30.8 \\
\hline Motor complete & 30 & 16.2 \\
\hline Motor incomplete & 24 & 13.0 \\
\hline Unknown & 3 & 1.6 \\
\hline
\end{tabular}

Abbreviations: AIS, The American Spinal Injury Association Impairment scale; TSCI, traumatic spinal cord injury.

aMotor complete lesion: AIS A+B operative correction of intervertebral disc herniations (5), pre-existing SCIs (3), non-traumatic spinal cord damage, for example,, metastatic cancer (4), a variety of other diagnoses (22) or there was no further information ( 13 records mentioned earlier).

To estimate the incidence of TSCI in the Netherlands in 2010, we calculated the ratio of TSCI patients (185) from the records for which we got information about (416), applied this ratio to the total number of records identified from the national database (486), including a correction for the estimated number of records from the hospitals that did not contribute data to the national database (35.2). In formula: $(185 / 416) \times(486+35.2) / 16.6=14.0$ per million per annum. Likewise, the incidence of TSCI surviving the acute phase was calculated as: $(155 / 416) \times(486+35.2) / 16.6=11.7$ per million per annum.

Further analyses were performed using data on the 185 patients with TSCI (Table 1). The male/female ratio was 2.9:1. Median age was 62 years (range 13-96 years, mean 56.2 years, s.d. 21.8) and the 61-70 group was the largest age group. Most patients had tetraplegia (69\%) and an motor incomplete lesion (62\%). Most patients (58\%) received a stabilizing operation following their SCI.

Table 2 shows the cause of injury. The leading cause was falls (53\%). Same-level falls accounted for TSCI in three cases aged $<51$ years (all motor incomplete) and 42 cases aged $>50$ years ( 9 motor

\section{Table 2 Cause of injury of patients with TSCI $(N=185)$}

\begin{tabular}{|c|c|c|}
\hline Cause & $\mathrm{N}$ & $\%$ \\
\hline Traffic & 40 & 21.6 \\
\hline Pedestrian & 1 & 0.5 \\
\hline Bicycle & 8 & 4.3 \\
\hline Moped & 3 & 1.6 \\
\hline Motorcycle & 11 & 5.9 \\
\hline Car & 15 & 8.1 \\
\hline Mobility scooter & 1 & 0.5 \\
\hline Not specified & 1 & 0.5 \\
\hline Sports & 26 & 14.1 \\
\hline Trampoline jumping & 1 & 0.5 \\
\hline Diving & 7 & 3.8 \\
\hline Biking & 6 & 3.2 \\
\hline Mountain biking & 2 & 1.1 \\
\hline Skiing & 2 & 1.1 \\
\hline Horse riding & 2 & 1.1 \\
\hline Motor cross & 2 & 1.1 \\
\hline Tennis & 1 & 0.5 \\
\hline Abseiling, paragliding & 2 & 1.1 \\
\hline Not specified & 1 & 0.5 \\
\hline Fall & 98 & 53.0 \\
\hline Same-level fall & 45 & 24.3 \\
\hline Fall from height & 49 & 26.4 \\
\hline Suicide attempt: jump/fall from height & 4 & 2.2 \\
\hline Violence & 3 & 1.6 \\
\hline Gunshot wound & 2 & 1.1 \\
\hline Stab wound & 1 & 0.5 \\
\hline latrogenic & 2 & 1.1 \\
\hline Fallen tree branch & 4 & 2.2 \\
\hline Other & 7 & 3.8 \\
\hline Unknown & 5 & 2.7 \\
\hline
\end{tabular}

Abbreviation: $\mathrm{TSCl}$, traumatic spinal cord injury. 
complete and 33 motor incomplete). Pre-existing stenosis of the spinal channel was found in 68 of 128 tetraplegic patients; most of these were elderly patients.

Mean duration of hospital stay, total hospital stay if patients went to several hospitals, was 24.7 days (median 17 days, range 0-136 days, s.d. 28.0). The discharge destination is shown in Table 3. Thirty patients died in the hospital phase and 91 patients were directly referred for rehabilitation. Discharge destination of survivors with motor complete TSCI was specialized inpatient rehabilitation in $78 \%$ and nursing home in $17 \%$ of cases (Table 4). The discharge destination of survivors with motor incomplete TSCI was specialized inpatient rehabilitation in $47 \%$ and nursing home in $26 \%$ of cases. Median age was associated with discharge destination. Median age of the deceased was 80 years, of survivors who went to a nursing home 77 years, and of those referred to (specialized) rehabilitation was 49 years (Table 4).

\section{Non-response analysis}

Fifteen general hospitals declined participation for a total of 67 records. Using the summary information performed by DHD, we were able to compare these with the 211 records of the 54 participating general hospitals to assess bias. All trauma centres participated in the study, therefore non-participating general hospitals were compared with participating general hospitals, as trauma centres and general hospitals treat distinct patient populations. The 211 records of the participating general hospitals had more males $(65.9 \%)$ than the 67 records of the non-participating hospitals $(52.2 \%$; $P$

Table 3 Discharge destination of patients with TSCI $(N=185)$

\begin{tabular}{lrr}
\hline Destination & N & $\%$ \\
\hline Rehabilitation total & 91 & 49.2 \\
Clinic specialized in SCl & 72 & 39.0 \\
Clinic not specialized in SCI & 7 & 3.8 \\
Outpatient & 8 & 4.4 \\
Not specified & 4 & 2.2 \\
& & \\
Deceased & 30 & 16.2 \\
Nursing home total & 25 & 13.5 \\
Permanent stay & 4 & 2.2 \\
Reactivation & 15 & 8.1 \\
Not specified & 6 & 3.2 \\
Other acute-care hospital & 21 & 11.4 \\
Home & 13 & 7.0 \\
Unknown & 5 & 2.7 \\
\hline
\end{tabular}

Abbreviation: TSCl, traumatic spinal cord injury.

a Outpatient in hospital or rehabilitation centre are not specialized in $\mathrm{SCl}$.
0.044). Other parameters were almost equal: mean age, s.d. and $95 \%$ confidence interval (CI) were 62.4 years; 18.7 and $57.9-66.9$ in the non-participating hospitals and 56.3 years; 21.6 and $53.4-59.2$ in the participating hospitals; mean hospital stay, s.d. and 95\% CI were 9.5 days; 8.1 and 5.0-14.0 in the non-participating hospitals and 9.3 days; 12.6 and 7.6-11.0 in the participating hospitals; No significant difference in discharge destination was found $(P=0.322)$.

\section{Comparison between 1994 and 2010}

Table 5 shows a comparison of the results of the current study with those of the 1994 study. ${ }^{1}$ The overall incidence of TSCI was not significantly different between both time periods. The incidence in women slightly increased. The age-specific incidence of TSCI, however, was clearly different, with much more elderly patients diagnosed with TSCI in 2010 compared with 1994. Pre-existing stenosis in tetraplegic patients, incomplete lesions and stabilizing surgery also increased, and mean length of hospital stay decreased (1994 31 days; 201025 days with 95\% CI 20.7-28.7 days).

\section{DISCUSSION}

The estimated incidence of traumatic SCI is 14.0 per million per annum, or 11.7 per million per annum for patients with TSCI surviving the acute phase. Mean age was high and a substantial part of this group was not referred to a specialized rehabilitation centre.

\section{Limitations}

Although we put much effort into the data collection, some hospitals declined participation and in some cases the hospital discharge letters did not contain sufficient information. Therefore, our incidence figures are estimations. We have, however, little indication for selection bias. Second, we checked the retrieved records for TSCI, but were not able to check how many not-retrieved records should have been coded as TSCI. So we might have missed TSCI cases and thereby have provided an underestimation as in our earlier study. We did not include individuals with TSCI who died at the scene, conform our earlier study, providing an underestimation of the total number of TSCI. This, however, has no consequences for the number of patients with TSCI admitted to an acute-care hospital or surviving the acute phase. The number of TSCI for the age $0-10$ years is zero, we do not have an explanation for this puzzling low number. In The Netherlands, individuals with TSCI are always admitted to an acutecare hospital, we did not miss patients admitted to a rehabilitation centre directly.

\section{Comparison with other studies}

In the literature, reported incidence of TSCI varies widely. ${ }^{2-4,6-11}$ This variation is partly because of differences in definition, classification

Table 4 Associations between discharge destination, type of $\mathrm{TSCl}$ and age $(N=159)$

\begin{tabular}{|c|c|c|c|c|}
\hline & Clinical rehabilitation (specialized) & Nursing home & Home, with or without therapy & Deceased \\
\hline$T S C I(N)$ & $83(72)$ & 25 & 21 & 30 \\
\hline Tetra/motor complete & $11(11)$ & 4 & 0 & 13 \\
\hline Tetra/motor incomplete & $40(32)$ & 17 & 13 & 9 \\
\hline Tetra/unknown completeness & $0(0)$ & 0 & 1 & 3 \\
\hline Para/motor complete & $23(21)$ & 3 & 0 & 1 \\
\hline Para/motor incomplete & $9(8)$ & 0 & 7 & 2 \\
\hline Para/unknown completeness & $0(0)$ & 1 & 0 & 2 \\
\hline Median age, range (years) & $49,14-91(49,14-78)$ & $77,24-90$ & $57,15-83$ & $80,13-95$ \\
\hline
\end{tabular}

Abbreviation: $\mathrm{TSCl}$, traumatic spinal cord injury. 
Table 5 Comparison of 1994 and 2010 results $^{a}$

\begin{tabular}{|c|c|c|c|}
\hline & 1994 & 2010 & $\begin{array}{c}\text { P-value } \\
\text { (two-sided) }\end{array}$ \\
\hline \multicolumn{4}{|l|}{ Incidence of $T S C I^{\mathrm{b}, \mathrm{c}}$} \\
\hline All patients & 12.1 & 14.0 & 0.566 \\
\hline $\begin{array}{l}\text { In those surviving the } \\
\text { acute phase }\end{array}$ & 10.4 & 11.7 & 0.260 \\
\hline \multicolumn{4}{|l|}{ Gender-specific incidence } \\
\hline In males & 18.6 & 20.9 & 0.480 \\
\hline In females & 5.4 & 7.2 & $<0.001$ \\
\hline \multicolumn{4}{|c|}{ Age-specific incidence (years) } \\
\hline $0-20$ & 6.3 & 6.1 & 1.00 \\
\hline $21-40$ & 14.1 & 8.9 & 0.166 \\
\hline $41-65$ & 8.9 & 12.3 & $<0.001$ \\
\hline $66-80$ & 25.2 & 34.3 & $<0.001$ \\
\hline$>80$ & 16.1 & 54.3 & $<0.001$ \\
\hline \multicolumn{4}{|c|}{ Comparison of cases with $T S C I^{d}$} \\
\hline Gender, male & $87 / 113=77 \%$ & $137 / 185=74 \%$ & 0.569 \\
\hline \multicolumn{4}{|l|}{ Age (years) } \\
\hline $0-20$ & $15 / 113=13 \%$ & $19 / 185=10 \%$ & \\
\hline $21-30$ & $28 / 113=25 \%$ & $13 / 185=7 \%$ & \\
\hline $31-60$ & $36 / 113=32 \%$ & $56 / 185=30 \%$ & \\
\hline$>60$ & $34 / 113=30 \%$ & $97 / 185=52 \%$ & $<0.001$ \\
\hline Level of $\mathrm{SCl}$, tetraplegia & $65 / 113=58 \%$ & $128 / 185=69 \%$ & 0.041 \\
\hline $\begin{array}{l}\text { Tetraplegia and } \\
\text { pre-existing stenosis }\end{array}$ & $23 / 65=35 \%$ & $68 / 128=53 \%$ & 0.020 \\
\hline Injury severity AIS C $+D^{e}$ & $58 / 113=51 \%$ & $115 / 177=65 \%$ & 0.021 \\
\hline Aetiology ${ }^{f}$ & $55 / 109=50 \%$ & $98 / 180=54 \%$ & \\
\hline \multicolumn{4}{|l|}{ Fall } \\
\hline Traffic accident & $35 / 109=32 \%$ & $40 / 180=22 \%$ & \\
\hline Sports & $10 / 109=9 \%$ & $26 / 180=14 \%$ & \\
\hline Other & $9 / 109=8 \%$ & $16 / 180=9 \%$ & 0.230 \\
\hline Stabilizing surgery Yes & $50 / 113=44 \%$ & $107 / 185=58 \%$ & 0.048 \\
\hline \multicolumn{4}{|l|}{ Destinationg } \\
\hline Home $^{h}$ & $8 / 84=10 \%$ & $13 / 129=10 \%$ & \\
\hline Nursing home & $10 / 84=12 \%$ & $25 / 129=19 \%$ & \\
\hline Rehabilitation ${ }^{i}$ & $66 / 84=79 \%$ & $91 / 129=71 \%$ & 0.334 \\
\hline
\end{tabular}

ancluding the deceased (unless otherwise stated)

'TSCI, traumatic spinal cord injury.

Incidence numbers per million inhabitants per annum, statistics with Mid-P-Exact test. ${ }^{\mathrm{d}}$ Statistics with $\gamma^{2}$-test.

e Motor incomplete lesion: The American Spinal Injury Association Impairment scale C + D.

fExcluding unknown aetiology.

gExcluding the deceased and those who went to another hospital or unknown destination.

' Excluding outpatient rehabilitation.

including outpatient rehabilitation.

and procedures of patient identification and partly because of external factors such as, for example, (maintenance of) traffic rules, natural conditions and pre-hospital treatment. ${ }^{1,3,4,6,12}$ The incidence of TSCI of 11.7 per million per annum surviving the acute phase estimated in this study is only slightly and not significantly $>10.4$ reported for $1994 .^{1}$ This is still low compared with the mean incidence of 16 in Western Europe ${ }^{4}$ and recent figures found in other countries in Western Europe, which vary between 12.1 (Spain, survivors) and 26.3 (Norway, including those who died). ${ }^{7-11}$

We checked all ICD-9 codes 806 and 952 in the national hospital database, and found that only 185 out of 416 registries (44\%) concerned new TSCI cases according to our definition. In 1994, this was even less $(38 \%))^{1}$ This prevented a large overestimation of the incidence of SCI compared with using uncorrected data from the national registry. ${ }^{1,12}$

The proportion of road traffic accidents non-significantly decreased from $31 \%$ in 1994 to $22 \%$ in 2010 (Table 5), a trend mirroring a decline of death and wounded people in traffic accidents in the Netherlands in recent years (http://swov.nl) and in other developed countries. ${ }^{4}$ In other Western-European countries the percentage of traffic accidents as cause of TSCI varied from 23\% (Sweden) to $57 \%$ (Spain). ${ }^{7-10}$

Compared with the 1994 data, ${ }^{1}$ there is a clear increase in the proportion of people over 60 years old and pre-existing spinal stenosis, often suffering motor incomplete tetraplegia. The increase in age-specific incidence of TSCI in the elderly is in line with the international literature. ${ }^{2}$ The increase in age at injury is associated with the growing importance of (same level) falls as cause of SCI.,7,9 The increase of motor incomplete SCI compared with motor complete SCI correlates with recent findings in Ireland ${ }^{8}$ and Spain, ${ }^{7}$ and with findings from Western Norway, which show an increase in cervical motor incomplete spinal cord lesions in the last decades. ${ }^{9}$

Recent TSCI studies showed a bimodal age distribution, with a first peak in young adults between 15 and 29 years and a second peak in older adults ( $>64$ years)., ${ }^{2,9}$ A similar peak (21-30 years) existed in $1994,{ }^{1}$ but not any more in the current 2010 data, although the agespecific incidences did not change significantly between these time points. This is in line with recent epidemiological data from Sweden (2008), ${ }^{10}$ and indicates that TSCI is becoming more and more a condition in the elderly.

The male-female ratio of 2.9:1 is consistent with Dutch results from $1994(3.3: 1)^{1}$ and recent data from Sweden (2008: 3.3:1). ${ }^{10}$

\section{Implications}

The incidence of TSCI in the Netherlands remains among the lowest in the world. Road safety measures and other prevention programs may, in combination with favourable geographic circumstances, for example, a lack of mountains, contribute to this low incidence and serve as good examples for other countries. Falls are now by far the most prevalent cause of TSCI with more than half of all cases in the Netherlands, and will probably become the most prevalent cause of TSCI in other developed countries as well. ${ }^{4}$ Additional preventive measures should focus on declining the risk for falls.

The growing numbers of elderly people with newly acquired SCI pose specific challenges to the rehabilitation system. Elderly patients are often less physically capable to complete an intensive rehabilitation program and have usually lower goals regarding, for example, returning to independent living and working. Nursing homes, however, are not specialized in SCI and its many and complex secondary conditions. How to provide specialized care to this is a challenge for health-care planning in the coming years. Meanwhile, concentrating on the smaller number of young TSCI patients to rehabilitation centres specialized in SCI remains important. This way sufficient experience continues to exist for the treatment of patients with recent TSCI.

\section{DATA ARCHIVING}

Data are available on request.

\section{CONFLICT OF INTEREST}

The authors declare no conflict of interest. 


\section{ACKNOWLEDGEMENTS}

We thank DHD Foundation for their cooperation and the delivery of data out of the national registry LMR, we especially want to express our sincere gratitude to Peggy Helmyr for her constructive cooperation. We thank the participating hospitals, their staffs of care administration, their participating specialists and their secretaries.

1 van Asbeck FWA, Post MWM, Pangalila RF. An epidemiological description of spinal cord injuries in the Netherlands in 1994. Spinal Cord 2000; 38: 420-424.

2 van den Berg MEL, Castellote JM, Mahillo-Fernandez I, de Pedro-Cuesta J. Incidence of spinal cord injury worldwide: a systematic review. Neuroepidemiology 2010; 34: 184-192.

3 Wyndaele M, Wyndaele JJ. Incidence, prevalence and epidemiology of spinal cord injury: what learns a worldwide literature survey? Spinal Cord 2006; 44: 523-529.

4 Lee BB, Cripps RA, Fitzharris M, Wing PC. The global map for traumatic spinal cord injury epidemiology: update 2011, global incidence rate. Spinal Cord 2014; 52: 110-116.
5 Kirshblum S, Burns S, Biering-Sorensen F, Donovan W, Graves D, Jha A et al. International standards for neurological classification of spinal cord injury (revised 2011). J Spinal Cord Med 2011; 34: 535-546.

6 Chiu WT, Lin HC, Lam C, Chu SF, Chiang YH, Tsai SH. Epidemiology of traumatic spinal cord injury: comparisons between developed and developing countries. Asia Pac J Public Health 2010; 22: 9-18.

7 van den Berg M, Castellote JM, Mahillo-Fernandez I, de Pedro-Cuesta J. Incidence of traumatic spinal cord injury in Aragon, Spain (1972-2008). J Neurotrauma 2011; 28: 469-477.

8 O'Connor RJ, Murray PC. Review of spinal cord injuries in Ireland. Spinal Cord 2006; 44: 445-448.

9 Hagen EM, Eide GE, Rekand T, Gilhus NE, Gronning M. A 50-year follow-up of the incidence of traumatic spinal cord injuries in Western Norway. Spinal Cord 2010; 48 : 313-318.

10 Divanoglou A, Levi R. Incidence of traumatic spinal cord injury in Thessaloniki, Greece and Stockholm, Sweden: a prospective population-based study. Spinal Cord 2009; 47: 796-801.

11 Albert T, Ravaud JF. Rehabilitation of spinal cord injury in France: a nationwide multicentre study of incidence and regional disparities. Spinal Cord 2005; 43 . 357-365.

12 Hagen EM, Rekand T, Gilhus NE, Gronning M. Diagnostic coding accuracy for traumatic spinal cord injuries. Spinal Cord 2009; 47: 367-371. 